\title{
Dibujar la nación. La comisión corográfica en la Colombia del siglo XIX
}

\author{
Appelbaum, N. (2017). Dibujar la nación. La comisión corográfica en la Colombia del siglo XIX. \\ Bogotá: Uniandes-Fondo de Cultura Económica
}

\author{
Reseña elaborada por: Cristian Fabian López Romero*
}

\begin{abstract}
La reflexión sobre lo nacional y la construcción de la identidad nacional han sido parte integral de las investigaciones alrededor de una de las empresas más importantes del siglo xIX en Colombia: la Comisión Corográfica. En su libro, Nancy Appelbaum asume esta tarea dando cuenta de la relación entre los resultados de la Comisión y la consolidación de un ideario de nación; además, enfoca su análisis en los procesos que constituyeron el proyecto, sus avatares, desarrollo y trayectoria. Acude, para lograr este propósito, a los relatos y narrativas que se encuentran en los productos de esta empresa, como los reflejados en las láminas corográficas y en los diarios de quienes fueron partícipes de los viajes.
\end{abstract}

La autora procura dar cuenta de las contradicciones dadas en el desarrollo de la Comisión Corográfica en el transcurso de ocho capítulos y una introducción. Por un lado, evidencia la constante homogeneidad buscada por los viajeros y, en contraparte, la heterogeneidad hallada en el marco de la diversidad étnica y cultural del país; por otro, presenta la amplitud de interpretaciones e intenciones desplegadas a partir del trabajo de los comisionados, al igual que las disputas que emergieron a raíz de las observaciones y los registros, las cuales terminaron dificultando la publicación de los resultados globales luego de la muerte de Codazzi.

Para desarrollar los objetivos propuestos, Appelbaum presenta en los primeros dos capítulos un análisis general de los hechos cruciales que posibilitaron la conformación de la Comisión Corográfica. En primer lugar, expone la importancia de la geografía para la especulación política, destacando el aporte de Joaquín Acosta como reeditor en formato de libro de El semanario de Francisco José de Caldas. Entre otros hitos, ligados a un movimiento general de intelectuales que seguían la tradición ilustrada en Nueva Granada que inició con Humboldt, se destaca en el libro la participación de Tomás Cipriano de Mosquera por su interés en el desarrollo de estudios geográficos, pero también por impulsar y consolidar el proyecto de la Comisión en su presidencia. En esta misma línea, se resalta el papel de Agustín Codazzi y Manuel Ancízar como fundadores de la Comisión Corográfica. La autora rescata la relación de ambos personajes con la República de Colombia, sus idearios y formación. Primordialmente, se exalta el trabajo de Codazzi en la Comisión realizada en Venezuela como un proceso que ayudó a consolidar un método corográfico que se replicó en Colombia, pero que a fin de cuentas terminó truncado por los conflictos políticos que se dieron en la época y que condicionaron la presentación de los resultados que se fueron obteniendo, principalmente en la consolidación de un mapa del territorio.

Los recorridos que se hicieron sobre la región nororiental y Antioquia en los dos primeros años de la Comisión se presentan en el tercer capítulo del libro. Allí se destacan los principales registros de los expedicionarios y sus diferentes interpretaciones construidas a partir de estos, lo que permite evidenciar que las observaciones empíricas no siempre coincidieron con las generalizaciones realizadas por los comisionados, tal y como se plasmó en la obra de Ancízar La peregrinación del alpha. Las generalizaciones que proyectaron los viajeros entrevén la incongruencia entre la búsqueda de una "raza granadina", vinculada a la tipología descrita por Manuel Ancízar y representada en las láminas corográficas, y la diversidad étnica como parte fundante de la nación colombiana. La autora resalta las diferencias advertidas, con relación al 
centro del país, en los resultados presentados sobre el viaje al Pacífico y la región suroccidental. Señala la evidente mirada determinista de los comisionados, quienes validaron la relación entre clima y grados de desarrollo social, así como la mirada sobre el negro como mano de obra y encarnación de la barbarie. Aquí da cuenta de las diferencias en cuanto a las propuestas de formación e instrucción partiendo de la intervención violenta deseada sobre los pobladores del Pacífico, por cuanto se presumía la negativa de esta raza a acatar normas y a civilizarse con el paso del tiempo, expresión de un regreso a las políticas y concepciones coloniales.

Una descripción final sobre los territorios visitados se encuentra en el capítulo cuatro, dedicado a las expediciones de los Llanos y a la Amazonía. En este, se señalan las dificultades de acceso a las regiones, los pocos caminos y las adversidades ligadas a la comunicación interregional. Se muestra la necesidad de los comisionados de depender de cargueros para movilizarse, así como de recurrir a los relatos y a los conocimientos de la población nativa para dar cuenta del territorio, cosa que sería blanco de crítica más adelante en la presentación de los resultados. Appelbaum también muestra en este capítulo la incongruencia de los datos sobre la población, donde se pinta el territorio como deshabitado. Señala el desconocimiento sobre las comunidades indígenas y su caracterización errónea como seres violentos y carentes de conciencia.

El capítulo quinto expone una mirada general acerca de las posibilidades económicas de la nación. Las diferentes rutas decimonónicas, vías (férreas, navegables y caminos) que se podían explotary desarrollar, a fin de superar uno de los obstáculos para la consolidación de un mercado interno y externo, dan cuenta de una perspectiva amplia sobre la producción en el territorio nacional. La tierra terminó cobrando relevancia respecto de la explotación y se concibió como esencial para incentivar los ciclos de intercambio, pero al mismo tiempo fue ignorada por la población de la época que desaprovechó sus capacidades productivas. Se destaca, además, el trabajo artesanal en el marco de una mirada optimista sobre la consolidación de procesos de exportación, lo cual incentivó la dinamización del mercado en el país.
En los capítulos finales aparecen las tensiones generadas alrededor de los resultados y su publicación. La autora confronta miradas sobre quiénes construían el imaginario de nación y sobre los fundamentos en los cuales se basaban, debido a unos resultados que presentaban un territorio atado a la región Andina del país que justificaba la integración de grupos minoritarios y la centralización del poder en Bogotá. Las dificultades que se dieron a la hora de publicar los resultados, los conflictos por las posiciones políticas y científicas que los diferentes actores tenían al respecto, junto a los productos construidos en las expediciones adelantadas, también fueron parte de un proyecto descrito por Appelbaum como ambicioso y contundente para el siglo xix colombiano. En el libro, las láminas como recurso para la descripción corográfica cobran especial protagonismo; algunas se analizan abordando la mirada que tenían los comisionados de las regiones representadas, sus habitantes y costumbres practicadas. De esta manera se consolida una narrativa general del desarrollo de la Comisión y de sus participantes.

En conclusión, el libro que presenta Appelbaum invita a pensar y repensar el papel de la Comisión Corográfica en la consolidación de la nación y de la identidad nacional en el siglo xIx, así como los elementos que hoy hereda la sociedad colombiana. Del mismo modo, invita a pensar en quiénes fueron sus partícipes y desde dónde se construye ese ideario de nación, donde las múltiples contradicciones que se generan alrededor de este proyecto son fundamentales a la hora de comprender el devenir de esta empresa, el análisis de sus resultados y las discusiones que estos generaron. 